(C)Carcinological Society of Japan. doi: 10.18353/crustacea.50.0_17

\title{
Seasonal variability in fecundity and egg size in the porcellanid crab Petrolisthes japonicus (Decapoda: Anomura: Porcellanidae)
}

\author{
Katsuyuki Hamasaki, Minako Ishii, Shigeki Dan
}

\begin{abstract}
We investigated the seasonal variability in fecundity and egg size in a Petrolisthes japonicus population by monthly sampling for one year on an intertidal cobble and boulder shore on the Boso Peninsula, Japan. Fecundity (number of eggs per brood) was determined for ovigerous females with non-eyed or eyed eggs in early (May and June), middle (July) and late (August and September) breeding periods. The long and short diameters of non-eyed eggs were measured, and the egg volume was calculated. Fecundity was positively correlated with female body size and found to be greater in the middle breeding period than in the early and late breeding periods. Egg loss occurred during embryogenesis, the egg loss rate being calculated as $44.6 \%$, $14.8 \%$ and $30.2 \%$ from the non-eyed to the eyed egg stages in the early, middle and late breeding periods, respectively. Egg size decreased linearly from the early to the late breeding periods. It is inferred that the seasonal variability in reproductive output, fecundity and egg size in $P$. japonicus may be regulated by female nutritional conditions and seasonal fluctuations of food production for larvae, as well as a trade-off between the number and size of eggs in a brood.
\end{abstract}

Key words: reproductive seasonality, reproductive output, reproductive traits, phenotypic plasticity, egg loss

Electronic supplementary material. The online version of this article contains supplementary material at https://www.jstage.jst.go.jp/article/crustacea/50/0/50_17/_article

\section{$\square$ Introduction}

Decapod crustaceans belonging to the Suborder Pleocyemata, such as lobsters, crayfishes, caridean shrimps, anomuran crabs and brachyuran crabs, brood eggs underneath the pleon, whereas those belonging to the Suborder Dendrobranchiata, such as penaeid prawns, spawn eggs directly into the water (Fernández et al., 2020). Reproductive output (the amount of energy allocated to egg production in terms of biomass) is principally determined by female body size because of allometric constraints on space available for yolk accumulation within the cephalothorax (Hines, 1982; Corey \& Reid,
1991; Reid \& Corey, 1991). The fecundity (number of eggs per brood) is determined by the average egg size of a brood, owing to a trade-off between egg size and number within an ovary with a designated biomass for producing a brood (Hines, 1982). In general, egg size is positively correlated with the size of newly hatched larvae (Hines, 1986; Hancock, 1998; Hamasaki et al., 2003; Bas et al., 2007; Gebauer et al., 2013).

The life-history trait of producing few and large eggs has often been considered as an evolutionary adaptation to aquatic environments with insufficient, unpredictable or seasonally short production of food for larvae (Anger, 
2001, 2006). Reproductive traits such as fecundity and egg size are thus particular to each species; however, the intraspecific variability in reproductive output, fecundity and egg size has been known to occur in several decapod crustacean species, depending on regionally and/or seasonally varying environmental conditions, such as temperature, salinity and food production (Sampedro et al., 1997; Paschke et al., 2004; Leme, 2006; Bas et al., 2007; Terossi et al., 2010; Wehrtmann et al., 2012; Gebauer et al., 2013; Urzúa \& Anger, 2013; Guzmán et al., 2016; Sato et al., 2017; Baldanzi et al., 2018). Information on the intraspecific variability in fecundity and egg size is thus crucial to infer the reproductive potential and future stock size of a decapod crustacean population.

Anomuran crabs of the family Porcellanidae Haworth, 1825 exhibit a brachyuran crab-like body shape with broad and dorsoventrally flattened chelipeds and a well-developed, symmetrical pleon that is carried bent under the cephalothorax and held against the thorax (Jones, 1977; Osawa \& McLaughlin, 2010). Petrolisthes japonicus (De Haan, 1849), one of the most common porcellanid crabs in Japan, is found on intertidal cobble and boulder shores in temperate and tropical regions (Miyake, 1998). It has been reported that the main reproductive season of $P$. japonicus lasts for approximately 4-5 months during the spring and summer seasons, based on the proportions of ovigerous females occurring in the populations (Nakasone, 1972; Hamasaki et al., 2020).

It is thus expected that the fecundity and egg size of $P$. japonicus may vary during the relatively longer reproductive season. However, no information is available for fecundity and egg size in P. japonicus, except for that provided by Nakasone (1972), who reported the mean number of eggs in five body-size classes as 30 381 eggs and the mean long and short diameters of eggs as $0.75 \times 0.67 \mathrm{~mm}$. The aim of the present study was to investigate the seasonal variability in fecundity and egg size in a $P$. japonicus population by conducting monthly sampling for one year on an intertidal cobble and boulder shore on the Boso Peninsula, Japan.

\section{$\square$ Materials and Methods}

\section{Crab sampling and measurements}

We used $P$. japonicus samples collected in our previous study for examining the reproductive season and population structure of this species (Hamasaki et al., 2020). Briefly, monthly sampling was conducted from April 2008 to March 2009 in an intertidal cobble and boulder zone $\left(34^{\circ} 58^{\prime} \mathrm{N}, 139^{\circ} 46^{\prime} \mathrm{E}\right)$ on the Boso Peninsula, Japan. The crab specimens were brought to the laboratory and kept in the freezer.

After thawing the frozen specimens, the carapace width $(\mathrm{CW}$, the widest portion between the lateral margins of the carapace) was measured using a digital calliper $(\mathrm{CW}>\sim 3 \mathrm{~mm}$, accuracy $0.05 \mathrm{~mm}$ ) or a stereomicroscope with the aid of a micrometer $(\mathrm{CW}<\sim 3 \mathrm{~mm}$, accuracy $0.01 \mathrm{~mm}$ ). The crabs with $>2.3 \mathrm{~mm} \mathrm{CW}$ were sexed based on the position of the gonopores (i.e. at the coxae of the third pereiopods in females and at the coxae of the fifth pereiopods in males) (Osawa \& McLaughlin, 2010) because the minimum body size of females has been found to be $2.3 \mathrm{~mm} \mathrm{CW}$ (Nakasone, 1972; Hamasaki et al., 2020).

Each female was classified according to the presence or absence of eggs attached to the pleopods (ovigerous or non-ovigerous females, respectively). To determine the fecundity of females, i.e. the number of eggs attached to the female pleopods, we carefully removed the eggs from each ovigerous female using forceps, and their embryonic development was classified into three stages under the stereomicroscope according to the following characteristics: non-eyed eggs, embryos without eye pigmentation; eyed eggs, embryos with eye pigmentation; and hatching eggs, fully devel- 
oped embryos with little or no yolk and any larvae that had emerged from the egg membrane. All the non-eyed and eyed eggs were counted, but the hatching eggs were not counted because some embryos might have been lost during the sampling operations.

Egg sizes were determined for the non-eyed stage because decapod crustacean eggs increase their volume during embryonic development, particularly during the eyed egg stage (e.g. Wear, 1974; Hamasaki et al., 2003). The long (L) and short (S) diameters (mm) of 10 non-eyed eggs from each specimen of a subsample of the monthly collected ovigerous females were measured under a microscope with the aid of a micrometer (accuracy $0.001 \mathrm{~mm}$ ); the number of female specimens was 17,28 and 7 individuals in June, July and August 2008 , respectively. The egg volume $\left(\mathrm{mm}^{3}\right)$ was calculated as $\left(1 / 6 \times \mathrm{L} \times \mathrm{S}^{2} \times \pi\right)$.

\section{Data analyses}

Statistical analyses were performed with $\mathrm{R}$ statistical software version 4.0.2 (R Core Team, 2020 ) at a $5 \%$ significance level. The relationship between the number of eggs attached to the pleopods (NE) and female body size (CW) was determined using a power function, $\mathrm{NE}=$ $a \mathrm{CW}^{\mathrm{b}}$, as applied for many decapod crustacean species (Somers, 1991), including porcellanid crabs (e.g. Jones, 1977; Gebauer et al., 2007; Pinheiro et al., 2017). The coefficients and standard errors were estimated by applying a general linear model ( $\mathrm{lm}$ function) to the logtransformed equation $\operatorname{lnNE}=\ln a+b \operatorname{lnCW}$.

In the present study, ovigerous females occurred in five successive months from May to September (155 individuals) and in February (one individual). To reveal the seasonal variability in the fecundity, log-transformed regression equations of fecundity were estimated for females with non-eyed or eyed eggs in three different periods, taking into account the seawater temperature profile (see Fig. S1 in the electronic supplementary material for the sea- water temperatures near the sampling site measured in the early and middle days of each month): early breeding period, May and June ( $\sim 18-20^{\circ} \mathrm{C}$ ); middle breeding period, July ( $\left.20-23^{\circ} \mathrm{C}\right)$; and late breeding period, August and September $\left(\sim 26-27^{\circ} \mathrm{C}\right)$. An ovigerous female collected in February was included temporarily in the late period. The outlier was excluded from the regression analyses with the aid of Cook's distance (Cook, 1977), using the cutoff point of $4 /(n-k-1)$, where $n$ is the number of samples and $k$ is the number of explanatory variables (Fox, 2008). The Cook's distance was calculated using the cooks.distance function.

Analysis of covariance (ANCOVA) was employed to compare differences in slopes and adjusted means of the response variable (lnNE) among/between log-transformed regression equations using the covar.test function (http:// aoki2.si.gunma-u.ac.jp/R/covar-test.html). Because significant differences were not detected in the slopes of regression equations among any comparisons, adjusted mean values with $95 \%$ confidence intervals of the response variable (lnNE) were calculated using the lsmeans function (Lenth, 2016), based on the log-transformed equations with the same slope and different intercepts. These adjusted means (lnNE) were converted to antilogarithmic numbers. In decapod crustacean species, eggs are lost from female pleopods owing to various abiotic and biotic factors during embryogenesis (Kuris, 1991). The egg loss rate was also calculated using the estimated adjusted means of noneyed and eyed eggs in each breeding period for $P$. japonicus.

One-way analysis of variance was employed to compare the egg sizes in different breeding periods after testing the relationship between the female body size (CW) and egg size (egg volume) using a Pearson correlation coefficient with a $t$-test, because female body size is known to affect the egg size in several decapod crustacean species (e.g. Gardner, 1997; Moland 
Table 1. Collection records for the porcellanid crab Petrolisthes japonicus from April 2008 to March 2009 on an intertidal cobble and boulder shore on the Boso Peninsula, Japan

\begin{tabular}{lccccc}
\hline \multirow{2}{*}{ Month } & $\begin{array}{c}\text { Non-ovigerous } \\
\text { females }\end{array}$ & Total & Non-eyed egg stage & Eyed egg stage & Hatching egg stage \\
\cline { 3 - 6 } April & 40 & 0 & 0 & 0 & 0 \\
May & 80 & 6 & 6 & 0 & 0 \\
June & 15 & 59 & 30 & 24 & 5 \\
July & 9 & 52 & 30 & 19 & 3 \\
August & 12 & 29 & 12 & 6 & 5 \\
September & 38 & 9 & 2 & 0 & 0 \\
October & 15 & 0 & 0 & 0 & 0 \\
November & 12 & 0 & 0 & 0 & 0 \\
December & 39 & 0 & 0 & 0 & 0 \\
January & 60 & 0 & 1 & 0 & 0 \\
February & 48 & 1 & 0 & 0 & 0 \\
March & 44 & 0 & 81 & 61 & 0 \\
\hline \multicolumn{1}{c}{ Total } & 412 & 156 & & 0 & 0 \\
\hline
\end{tabular}

\section{(A) Non-eyed eggs}

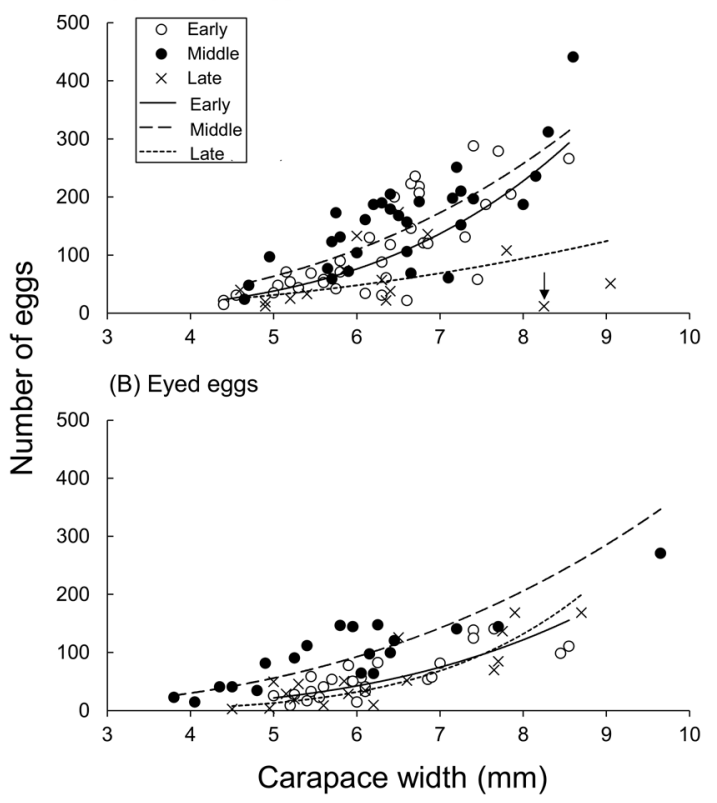

Fig. 1. Numbers of non-eyed eggs (A) and eyed eggs (B) attached to the female pleopods in relation to the carapace width of the porcellanid crab Petrolisthes japonicus collected in early (May and June), middle (July), and late (August, September and February) breeding periods. Arrow indicates the female with non-eyed eggs collected in February that exhibited a large Cook's distance value, and this outlier was excluded from the regression analysis (see supplementary Fig. S2 and Table S1 for the Cook's distance analysis). Curves were drawn based on the log linear regression equations between carapace width and number of eggs estimated for respective breeding periods (see Table 2). et al., 2010; Sato \& Suzuki, 2010).

\section{Results}

We collected 568 females, including 156 ovigerous females (81 non-eyed, 61 eyed and 14 hatching egg stages) during the sampling period (Table 1). The mean \pm standard deviation (range) of the $\mathrm{CW}$ values of the specimens was, for overall females, $5.18 \pm 1.56(2.31-$ $9.65) \mathrm{mm}$, and, for ovigerous females, $6.21 \pm$ $1.10(3.80-9.65) \mathrm{mm}$. Ovigerous females were found from May to September and in February, and egg hatching occurred from June to September (Table 1). In February, only one ovigerous female $(8.25 \mathrm{~mm} \mathrm{CW})$ with non-eyed eggs was detected.

The numbers of non-eyed eggs and eyed eggs attached to the female pleopods varied from 12 to 441 and from 3 to 271 , respectively. The number of eggs tended to increase with increasing female body size (Fig. 1), and the logtransformed regression equations between these variables were statistically significant for respective breeding periods in both egg stages (Table 2), except for the non-eyed egg stage in the late breeding period (see supplementary Table S1). In the late breeding period, however, 
Table 2. Log linear regression analyses $(\operatorname{lnNE}=\ln a+b \operatorname{lnCW})$ evaluating the relationships between carapace width (CW) and number of non-eyed eggs or eyed eggs (NE) attached to the female pleopods of the porcellanid crab Petrolisthes japonicus collected in early (May and June), middle (July) and late (August and September) breeding periods

\begin{tabular}{|c|c|c|c|c|c|c|c|}
\hline \multirow{2}{*}{ Egg stage } & \multirow{2}{*}{ Period } & \multicolumn{2}{|c|}{ Coefficients } & \multirow{2}{*}{$R^{2}$} & \multirow{2}{*}{$F$} & \multirow{2}{*}{$d f$} & \multirow{2}{*}{$P$} \\
\hline & & $\ln a$ & $b$ & & & & \\
\hline \multirow[t]{3}{*}{ Non-eyed } & Early & -2.4877 & 3.8063 & 0.5869 & 48.31 & 1,34 & $<0.0001$ \\
\hline & Middle & -0.6377 & 2.9767 & 0.5653 & 36.41 & 1,28 & $<0.0001$ \\
\hline & Late & -0.3138 & 2.3368 & 0.2860 & 4.81 & 1,12 & 0.0488 \\
\hline \multirow[t]{3}{*}{ Eyed } & Early & -2.8266 & 3.6686 & 0.5919 & 31.90 & 1,22 & $<0.0001$ \\
\hline & Middle & -0.4355 & 2.7718 & 0.7537 & 52.03 & 1,17 & $<0.0001$ \\
\hline & Late & -5.3375 & 4.9155 & 0.6073 & 24.75 & 1,16 & 0.0001 \\
\hline
\end{tabular}

(A)

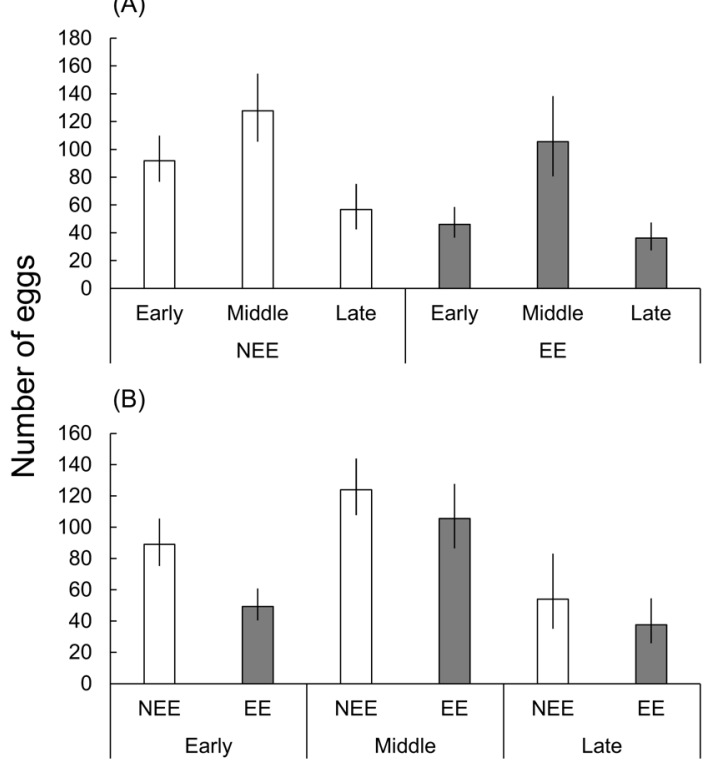

Egg stage and breeding period

Fig. 2. Adjusted mean values with $95 \%$ confidence intervals of the number of eggs attached to the female pleopods of the porcellanid crab Petrolisthes japonicus, estimated using the log-transformed equations with the same slope and different intercepts for three different breeding periods in two different egg stages (A) and those for two different egg stages in three different breeding periods (B). Breeding period: early (May and June), middle (July) and late (August and September) periods. Egg stage: non-eyed egg (NEE) and eyed egg (EE) stages. Vertical lines indicate the $95 \%$ confidence intervals.

regression equation became statistically significant after removing the data set of the unseasonal ovigerous female collected in February that exhibited a large Cook's distance value (see supplementary Fig. S2 and Table S1). The statistically significant equation (Table 2) was thus used for the subsequent ANCOVA.

In both egg stages, a significant difference was not found in slopes (non-eyed eggs, $F_{2,74}$ $=1.295, P=0.2800$; and eyed eggs, $F_{2,55}=$ $2.785, P=0.0705)$ but was detected in adjusted means of the response variable (non-eyed eggs, $F_{2,76}=11.139, P<0.0001 ;$ and eyed eggs, $F_{2,57}$ $=17.589, P<0.0001)$ among equations for different breeding periods. The estimated adjusted mean of the fecundity tended to be larger in the middle period than in the early and late periods (Fig. 2A; see supplementary Table S2 for the mean values with $95 \%$ confidence intervals of fecundity). When log-transformed equations of fecundity were compared between non-eyed and eyed egg stages in each breeding period, the slopes were not significantly different in all periods (early period, $F_{1,56}=0.0248$, $P=0.8755$; middle period, $F_{1,45}=0.107, P=$ 0.7457 ; and late period, $F_{1,28}=3.074, P=$ 0.0905 ), and the adjusted means of the response variable were significantly different in the early breeding period $\left(F_{1,57}=19.450, P<\right.$ $0.0001)$ but not in the middle $\left(F_{1,46}=1.918, P\right.$ $=0.1728)$ and late breeding periods $\left(F_{1,29}=\right.$ $1.718, P=0.2002)$. Nevertheless, the estimated adjusted mean of the fecundity tended to be larger at the non-eyed egg stage than at the eyed egg stage (Fig. 2B; see supplementary Table S3 for the mean values with $95 \%$ confi- 
(A)

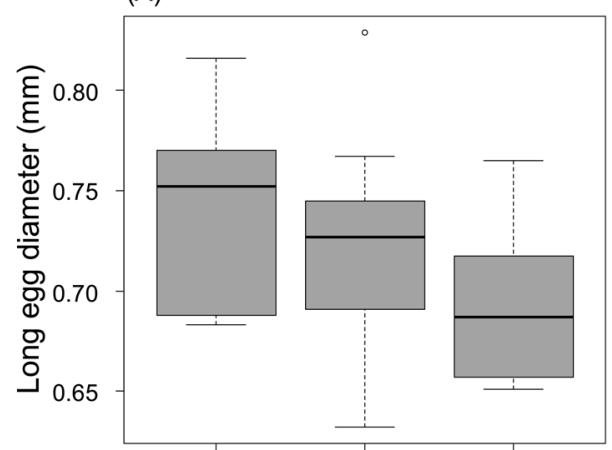

(B)

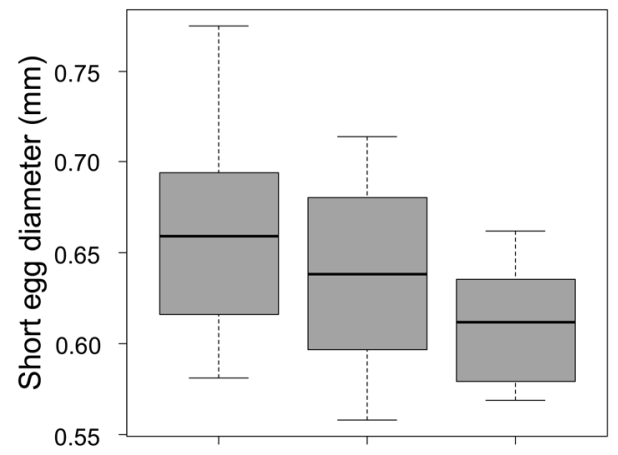

(C)

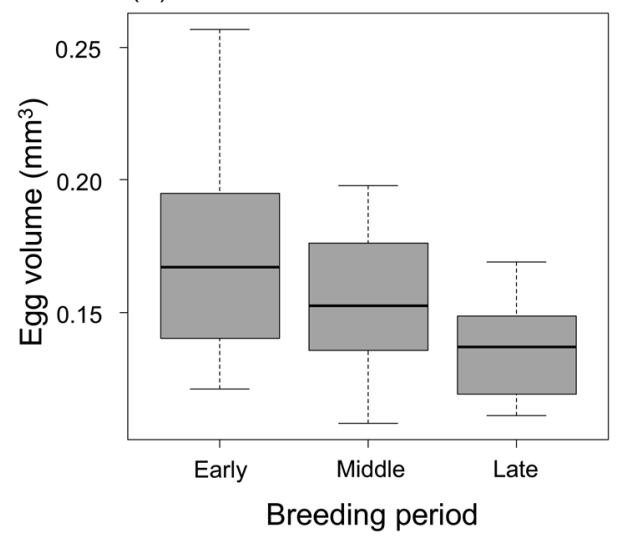

Fig. 3. Box plots of the long diameter (A), short diameter (B) and volume (D) of non-eyed eggs of the porcellanid crab Petrolisthes japonicus collected in early (June), middle (July) and late (August) breeding periods. Number of females measured was 17, 28 and 7 individuals in the early, middle and late breeding periods, respectively.

dence intervals of fecundity). The egg loss rate was thus calculated as $44.6 \%, 14.8 \%$ and $30.2 \%$ from the non-eyed to the eyed egg stages in the early, middle and late breeding peri- ods, respectively.

The egg volume was not correlated with female body size in respective breeding periods (early period, $r=0.0091, n=17, t=0.0353, P$ $=0.9723$; middle period, $r=0.2833, n=28, t$ $=1.5060, P=0.1441$; and late period, $r=$ $0.3269, n=7, t=-0.7735, \mathrm{P}=0.4742$; see supplementary Fig. S3). The egg sizes varied among different breeding periods (long diameter, $F_{2,49}=3.401, P=0.0414$; short diameter, $F_{2,49}=2.559, P=0.0877$; egg volume, $F_{2,49}=$ $3.576, P=0.0355)$, and the egg sizes tended to decrease linearly from the early to the late breeding periods (Fig. 3; see supplementary Table S4 for the mean and standard deviation values of egg sizes).

\section{$\square$ Discussion}

The present study detected the seasonal variability in fecundity and egg size in porcellanid crab P. japonicus on the intertidal cobble and boulder shore on the Boso Peninsula, Japan (Figs. 1-3). Fecundity (i.e. number of eggs attached to the pleopods) increased with increasing female body size (Fig. 1), as is generally seen in decapod crustaceans (e.g. Hines, 1982; Corey \& Reid, 1991; Reid \& Corey, 1991; Somers, 1991), including porcellanid crab species (Jones, 1977; Hernáez \& Palma, 2003; Gebauer et al., 2007; Wehrtmann et al., 2012; Pinheiro et al., 2017).

Nakasone (1972) calculated the mean number of eggs attached to the pleopods in five body-size classes in a $P$. japonicus population on the intertidal shore at Tsuyazaki $\left(33^{\circ} 47^{\prime} \mathrm{N}\right.$, $\left.130^{\circ} 27^{\prime} \mathrm{E}\right)$, Fukuoka Prefecture, Japan. Although Nakasone (1972) did not refer the embryonic developmental stage of eggs, he stated that the mean fecundity increased linearly from 30 to 381 eggs with increasing body-size class of $P$. japonicus females. The fecundity of $P$. japonicus, 12-441 eggs (non-eyed eggs in the present study) and 30-381 eggs (Nakasone, 1972), was equivalent to that of Petrolisthes 
species with similar body size and egg volume to $P$. japonicus (Hernáez \& Palma, 2003; Wehrtmann et al., 2012).

In our $P$. japonicus population, the long and short diameters and the volume of the noneyed eggs decreased linearly from the early to the late breeding periods (Fig. 3; Table S4). Seasonal size variation has been known in eggs and larvae of several decapod crustacean species, the eggs and larvae becoming larger when they are spawned under cooler temperature conditions (Kobayashi \& Matsuura, 1995; Hamasaki et al., 2006; Fischer et al., 2009; Urzúa \& Anger, 2013; Sato et al., 2017).

Nakasone (1972) examined the occurrence pattern of non-ovigerous and ovigerous females with or without developed ovarian eggs in the Tsuyazaki P. japonicus population, reporting that females begin to develop ovarian eggs in April and may produce three broods per year as a first brood from the end of May, a second brood from the middle of July and a third brood from the end of August. In our $P$. japonicus population, it is inferred that females may spawn first, second and third broods in the early (May and June), middle (July) and late (August and September) breeding periods, respectively, and egg size may decrease with increasing ambient temperature during the period from April $\left(16.5^{\circ} \mathrm{C}\right)$ to August/September (26$27^{\circ} \mathrm{C}$ ) (Fig. S1).

It has been proposed that the increased oxygen demand of embryos and decreased oxygen solubility in seawater at higher temperatures act as a limiting factor on large eggs, owing to their low surface-to-volume ratio in the brachyuran crab Cancer setosus Molina, 1782 (Brante et al., 2003; Fischer et al., 2009). Besides the physiological aspect, the cause of intraspecific variability in offspring size of decapod crustaceans has been discussed in terms of an evolutionary adaptation of larvae to aquatic environments with fluctuating food production (Anger, 2001, 2006). For example, the North Sea shrimp Crangon crangon (Linnaeus, 1758) produces larger winter eggs and smaller summer eggs, and larger larvae hatched from winter eggs exhibit a stronger starvation resistance compared to smaller larvae hatched from summer eggs; nutritionally less vulnerable larger winter larvae are considered to adapt to their hatching season when plankton production is on average low or unpredictable (Paschke et al., 2004; Urzúa \& Anger, 2013).

The phenotypic plasticity in offspring size has been similarly considered an adaptation to regional and seasonal variabilities in food production for larvae in several decapod crustacean species (Leme, 2006; Bas et al., 2007; Guzmán et al., 2016; Sato et al., 2017), including the porcellanid crabs Pisidia longicornis (Linnaeus, 1767) (Sampedro et al., 1997) and Petrolisthes laevigatus (Guérin, 1835) (Gebauer et al., 2013). Larvae of $P$. japonicus prey on zooplankton (Osawa, 1995). The seasonal variability in egg size of $P$. japonicus may also be attributed to the change in production of prey zooplankton such as copepods, which generally increase from spring to summer in Tokyo Bay (Nomura et al., 1992; Ito \& Aoki, 2010), near the sampling site of $P$. japonicus in the present study.

Fecundity of $P$. japonicus was largest in the middle breeding period, followed by that in the early breeding period and being smallest in the late breeding period (Fig. 2A; Table S2). Therefore, the trade-off between number and size of eggs per brood appears to be found in the early breeding period (few large eggs) and middle breeding period (many small eggs) (Figs. 2A and 3). Here, we estimated the reproductive output in P. japonicus females by multiplying the adjusted mean of fecundity (Table S2) by egg volume (Table S4) determined for the non-eyed eggs in respective breeding periods as: $15.7 \mathrm{~mm}^{3}$ in early, $19.7 \mathrm{~mm}^{3}$ in middle and $7.7 \mathrm{~mm}^{3}$ in late periods.

Maternal nutritional conditions are likely to affect the reproductive output of decapod crustaceans (Palacios et al., 1999; Tropea \& Greco, 
2015). Females of $P$. japonicus begin ovarian development from April and spawn eggs from the end of May (Nakasone, 1972) before the zooplankton biomass increases (Nomura et al., 1992; Ito \& Aoki, 2010). Porcellanid crabs are suspension feeders, trapping suspended detritus and plankton by using the long setae of their third maxillipeds (Trager \& Genin, 1993; Achituv \& Pedrotti, 1999; Zimba et al., 2016). Zooplankton productivity may thus affect the nutritional conditions of $P$. japonicus females, and their increase in reproductive output from the early to the middle breeding periods may depend on the increase in the food zooplankton biomass (Nomura et al., 1992; Ito \& Aoki, 2010). P. japonicus produces at least three successive broods during one reproductive season (Nakasone, 1972); therefore, the lowest reproductive output in the late breeding period, even with the high zooplankton productivity (Nomura et al., 1992; Ito \& Aoki, 2010), may be a consequence of the reproductive exhaustion of the females (Palacios et al., 1999; Tropea \& Greco, 2015), as inferred for several decapod crustacean species (Leme, 2006; Bas et al., 2007; Sato et al., 2017).

Our fecundity analyses suggested that ovigerous females of $P$. japonicus lost approximately $45 \%, 15 \%$ and $30 \%$ of their eggs during embryogenesis from the non-eyed to the eyed egg stages in the early, middle and late breeding periods, respectively. Our estimates of egg loss rates are within the range of egg mortality reported for other Petrolisthes species (1546\%) (Jones, 1977; Lardies \& Wehrtmann, 1996; Wehrtmann et al., 2012). Egg loss occurs as a result of a variety of biotic and abiotic factors, such as a failure of the eggs to adhere to the pleopodal setae at oviposition, mechanical losses, egg mortality due to inappropriate temperature and salinity conditions and predation and parasitism (Kuris, 1991). In the early breeding period with lower temperature conditions, the egg incubation duration of $P$. japonicus is expected to be prolonged, as in many de- capod crustacean species (e.g. Wear, 1974; Hamasaki et al., 2003): prolonged egg incubation duration may increase the opportunities for the eggs to suffer damage. In the late breeding period, higher temperatures may enhance the activity of pathogenic organisms, such as infectious oomycetes in crab eggs (Hamasaki et al., personal observation).

The present study highlighted the intrapopulation variation in fecundity and egg size depending on the season in $P$. japonicus on the Boso Peninsula, Japan. Interpopulation variation in reproductive traits has been documented in decapod crustaceans (Brante et al., 2003; Bas et al., 2007; Fischer et al., 2009; Terossi et al., 2010; Baldanzi et al., 2018), including porcellanid crab species (Jones, 1977; Wehrtmann et al., 2012). P. japonicus is distributed from northern Japan $\left(40^{\circ} \mathrm{N}\right)$ to the subtropical islands of southern Japan $\left(24^{\circ} \mathrm{N}\right)$ (Miyake, 1998). Future studies targeting $P$. japonicus populations from northern to southern locations would contribute to understanding the interpopulation variation and its causes in the reproductive traits of this species, which has a broad geographical distribution.

\section{Acknowledgements}

We thank the members of the laboratory for helping with field and laboratory work. We are grateful to the editor and two anonymous reviewers for their valuable comments and suggestions, which have improved the manuscript.

\section{$\square$ Literature Cited}

Anger, K., 2001. The Biology of Decapod Crustacean Larvae. Crustacean Issues 14. 419 pp. A. A. Balkema, Lisse.

Anger, K., 2006. Contribution of larval biology to crustacean research: A review. Invertebrate Reproduction \& Development, 49: 175-205.

Achituv, Y., \& Pedrotti, M. L., 1999. Costs and 
gains of porcelain crab suspension feeding in different flow conditions. Marine Ecology Progress Series, 184: 161-169.

Bas, C. C., Spivak, E. D., \& Anger, K., 2007. Seasonal and interpopulational variability in fecundity, egg size, and elemental composition $(\mathrm{CHN})$ of eggs and larvae in a grapsoid crab, Chasmagnathus granulatus. Helgoland Marine Research, 61: 225-237.

Baldanzi, S., Storch, D., Navarrete, S. A., Graeve, M., \& Fernández, M., 2018. Latitudinal variation in maternal investment traits of the kelp crab Taliepus dentatus along the coast of Chile. Marine Biology, 165: 37.

Brante, A., Fernández, M., Eckerle, L., Mark, F., Pörtner, H.-O., \& Arntz, W., 2003. Reproductive investment in the crab Cancer setosus along a latitudinal cline: Egg production, embryo losses and embryo ventilation. Marine Ecology Progress Series, 251: 221-232.

Cook, R. D., 1977. Detection of influential observation in linear regression. Technometrics, 19: $15-18$.

Corey, S., \& Reid, D. M., 1991. Comparative fecundity of decapod crustaceans I. The fecundity of thirty-three species of nine families of caridean shrimp. Crustaceana, 60: 270294.

Fernández, M., Brante, A., \& Baldanzi, S., 2020. Costs and benefits of brooding among decapod crustaceans: The challenges of incubating in aquatic systems. In: R. D. Cothran, M. Thiel, (eds.), The Natural History of the Crustacea, Vol. 6: Reproductive Biology, Oxford University Press, New York, NY, pp. 86-114.

Fischer, S., Thatje, S., \& Brey, T., 2009. Early egg traits in Cancer setosus (Decapoda, Brachyura): Effects of temperature and female size. Marine Ecology Progress Series, 377: 193-202.

Fox, J., 2008. Applied Regression Analysis and Generalized Linear Models. 2nd edn. 688 pp. Sage Publications, Thousand Oaks, CA.

Gardner, C., 1997. Effect of size on reproductive output of giant crabs Peseudocarcinus gigas
(Lamarck): Oziidae. Marine and Freshwater Research, 48: 581-587.

Gebauer, P., Paschke, K., \& Moreno, C. A., 2007. Reproductive biology and population parameters of Petrolisthes laevigatus (Anomura: Porcellanidae) in southern Chile: Consequences on recruitment. Journal of the Marine Biological Association of the United Kingdom, 87: 729-734.

Gebauer, P., Paschke, K., Barría, A., \& Anger, K., 2013. Seasonal variation in dry weight and elemental composition of the early developmental stages of Petrolisthes laevigatus (Guérin, 1835) (Decapoda: Porcellanidae) in the Seno de Reloncaví, southern Chile. Helgoland Marine Research, 67: 167-177.

Guzmán, F., Olavarría, L., \& Urzúa, Á., 2016. Seasonal variation in reproductive parameters of the squat lobster Pleuroncodes monodon from a South Pacific population. Invertebrate Reproduction \& Development, 60: 137-144.

Hamasaki, K., Fukunaga, K., \& Maruyama, K., 2003. Egg development and incubation period of the swimming crab Portunus trituberculatus (Decapoda: Portunidae) reared in the laboratory. Crustacean Research, 32: 45-54.

Hamasaki, K., Fukunaga, K., \& Kitada, S., 2006. Batch fecundity of the swimming crab Portunus trituberculatus (Brachyura: Portunidae). Aquaculture, 253: 359-365.

Hamasaki, K., Ishii, M., \& Dan, S., 2020. Reproductive traits and population structure of the porcellanid crab Petrolisthes japonicus (Decapoda: Anomura: Porcellanidae). Crustacean Research, 49: 121-132.

Hancock, M. A., 1998. The relationship between egg size and embryonic and larval development in the freshwater shrimp Paratya australiensis Kemp (Decapoda: Atyidae). Freshwater Biology, 39: 715-723.

Hernáez, P., \& Palma, S., 2003. Fecundity, egg volume and reproductive performance of five species of intertidal porcelains from northern Chile (Decapoda, Porcellanidae). Investigaciones Marinas, 31: 35-46. (in 
Spanish with English abstract)

Hines, A. H., 1982. Allometric constraints and variables of reproductive effort in brachyuran crabs. Marine Biology, 69: 309-320.

Hines, A. H., 1986. Larval patterns in the life histories of brachyuran crabs (Crustacea, Decapoda, Brachyura). Bulletin of Marine Science, 39: 444-466.

Ito, H., \& Aoki, N., 2010. Temporal and spatial distribution of planktonic copepods in Tokyo Bay: Seasonal occurrence in the innermost part of the bay, in the early 1990s. Bulletin of the Plankton Society of Japan, 57: 94 104. (in Japanese with English abstract)

Jones, M. B., 1977. Breeding and seasonal population changes of Petrolisthes elongatus (Crustacea, Decapoda, Anomura) at Kaikoura, New Zealand. Journal of the Royal Society of New Zealand, 7: 259-272.

Kobayashi, S., \& Matsuura, S., 1995. Egg development and variation of egg size in the Japanese mitten crab Eriocheir japonicus (De Hann). Benthos Research, 48: 29-39.

Kuris, A. M., 1991. A review of patterns and causes of crustacean brood mortality. In: A. Wenner, A. Kuris, (eds.), Crustacean Egg Production, Crustacean Issues 7, A. A. Balkema, Rotterdam, pp. 117-141.

Lardies, M. A., \& Wehrtmann, I. S., 1996. Aspects of the reproductive biology of Petrolisthes laevigatus (Guérin, 1835) (Decapoda: Anomura: Porcellanidae). I. Reproductive output and chemical composition of eggs during embryonic development. Archive of Fishery and Marine Research, 43: 121-135.

Leme, M. H. A., 2006. Seasonal changes in reproductive traits of the crab Sesarma rectum (Grapsoidea: Sesarmidae) on the northern coast of São Paulo State, Brazil. Journal of Crustacean Biology, 26: 141-147.

Lenth, R. V., 2016. Least-squares means: The R package lsmeans. Journal of Statistical Software, 69(1): 1-33.

Miyake, S., 1998. Japanese Crustacean Decapods and Stomatopods in Color, Vol. I. Macrura, Anomura and Stomatopoda. Third Printing.
261 pp. Hoikusha, Osaka. (in Japanese)

Moland, E., Moland Olsen, E., \& Stenseth, N. C., 2010. Maternal influences on offspring size variation and viability in wild European lobster Homarus gammarus. Marine Ecology Progress Series, 400: 165-173.

Nakasone, Y., 1972. Observations of the reproductive cycle of Petrolisthes japonicus (De Haan) (Anomura: Porcellanidae). Bulletin of Science \& Engineering Division, University of Ryukyus. Mathematics \& Natural Sciences, 15: 127-135.

Nomura, H., Ishimaru, T., \& Murano, M., 1992. Microzooplankton assemblage and its seasonal variation in Tokyo Bay, Japan. La mer, 30: 57-72. (in Japanese with English abstract)

Osawa, M., 1995. Larval development of four Petrolisthes species (Decapoda: Anomura: Porcellanidae) under laboratory conditions, with comments on the larvae of the genus. Crustacean Research, 24: 157-187.

Osawa, M., \& McLaughlin, P. A., 2010. Annotated checklist of anomuran decapod crustaceans of the world (exclusive of the Kiwaoidea and families Chirostylidae and Galatheidae of the Galatheoidea) Part II Porcellanidae. The Raffles Bulletin of Zoology, Supplement 23: 109-129.

Palacios, E., Pérez-Rostro, C. I., Ramírez, J. L., Ibarra, A. M., \& Racotta, I. S., 1999. Reproductive exhaustion in shrimp (Penaeus vannamei) reflected in larval biochemical composition, survival and growth. Aquaculture, 171: 309-321.

Paschke, K. A., Gebauer, P., Buchholz, F., \& Anger, K., 2004. Seasonal variation in starvation resistance of early larval North Sea shrimp Crangon crangon (Decapoda: Crangonidae). Marine Ecology Progress Series, 279: 183-191.

Pinheiro, M. A. A., João, M. C. A., Leme, M. H. A., Matsunaga, A. M. F., Rio, J. P. P., \& Hernáez, P., 2017. Insights of the life history in the porcellanid crab Petrolisthes armatus (Gibbes, 1850) (Crustacea: Anomura: Por- 
cellanidae) from the Southwestern Atlantic coast. Invertebrate Reproduction \& Development, 61: 78-89.

R Core Team, 2020. R: A Language and Environment for Statistical Computing. R Foundation for Statistical Computing, Vienna. https://www.R-project.org/.

Reid, D. M., \& Corey, S., 1991. Comparative fecundity of decapod crustaceans, II. The fecundity of fifteen species of anomuran and brachyuran crabs. Crustaceana, 61: 175189.

Sampedro, M. P., Fernández, L., Freire, J., \& González-Gurriarán, E., 1997. Fecundity and reproductive output of Pisidia longicornis (Decapoda, Anomura) in the Ría de Arousa (Galicia, NW Spain). Crustaceana, 70: 95-110.

Sato, T., \& Suzuki, N., 2010. Female size as a determinant of larval size, weight, and survival period in the coconut crab, Birgus latro. Journal of Crustacean Biology, 30: 624-628.

Sato, T., Hamano, K., Sugaya, T., \& Dan, S., 2017. Effects of maternal influences and timing of spawning on intraspecific variations in larval qualities of the Kuruma prawn Marsupenaeus japonicus. Marine Biology, 164: 70

Somers, K. M., 1991. Characterizing size-specific fecundity in crustaceans. In: A. Wenner, A. Kuris, (eds.), Crustacean Egg Production, Crustacean Issues 7, A. A. Balkema, Rotterdam, pp. 357-378.

Terossi, M., Torati, L. S., Miranda, I., Scelzo, M. A., \& Mantelatto, F. L., 2010. Comparative reproductive biology of two southwestern Atlantic populations of the hermit crab Pagurus exilis (Crustacea: Anomura: Paguridae). Marine Ecology, 31: 584-591.

Trager, G., \& Genin, A., 1993. Flow velocity induces a switch from active to passive suspension feeding in the porcelain crab Petrolisthes leptocheles (Heller). The Biological
Bulletin, 185: 20-27.

Tropea, C., \& Greco, L. S. L., 2015. Female growth and offspring quality over successive spawning in a caridean shrimp Neocaridina davidi (Decapoda, Atyidae) with direct development. The Biological Bulletin, 229: 243-254.

Urzúa, Á., \& Anger, K., 2013. Seasonal variations in larval biomass and biochemical composition of brown shrimp, Crangon crangon (Decapoda, Caridea), at hatching. Helgoland Marine Research, 67: 267-277.

Wear, R. G., 1974. Incubation in British decapod Crustacea, and the effects of temperature on the rate and success of embryonic development. Journal of the Marine Biological Association of the United Kingdom, 54: 745762.

Wehrtmann, I. S., Miranda, I., Lizana-Moreno, C. A., Hernáez, P., Barrantes-Echandi, V., \& Mantelatto, F. L., 2012. Reproductive plasticity in Petrolisthes armatus (Anomura, Porcellanidae): A comparison between a Pacific and an Atlantic population. Helgoland Marine Research, 66: 87-96.

Zimba, P. V., Hill, E. M., \& Withers, K., 2016. Benthic microalgae serve as the major food resource for porcelain crabs (Petrolisthes spp.) in oyster reefs: Digestive track content and pigment evidence. Journal of Experimental Marine Biology and Ecology, 483: $53-58$.

\section{Addresses}

(KH) (MI) (SD) Department of Marine Biosciences, Tokyo University of Marine Science and Technology, Konan, Minato, Tokyo 108-8477, Japan

\section{E-mail address of corresponding author}

(KH)hamak@kaiyodai.ac.jp 